examined showed blood lead concentrations of $0.5 \mathrm{umol} / \mathrm{L}$ or more, which exceeded the acceptable CDC limits. At levels between 0.5 and $1.2 \mathrm{umol} / \mathrm{L}$, the free erythrocyte protoporphyrin (FEP) screening test was a very poor predictor of toxic blood lead values (Rifai $\mathrm{N}$ et al.

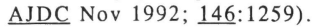

\title{
HEMOLYTIC-UREMIC ENCEPHALOPATHY
}

Twenty-seven children, ages 6 months - 13 years, with encephalopathy complicating hemolytic-uremic syndrome are reported from The University of British Columbia, Vancouver, Canada. Seventeen had seizures and 2 died. An increased risk for developing a neurological manifestation was correlated with the female sex, the prolonged use of an antimotility agent (e.g. codeine, anticholinergic drugs) and an increased hemoglobin (Cimolai $\mathrm{N}$ et al. Risk factors for the central nervous system manifestations of gastroenteritisassociated hemolytic-uremic syndrome. Pediatrics Oct 1992; 90:616-621. (Reprints: N. Cimolai, M.D., Department of Pathology, British Columbia's Children's Hospital, 4480 Oak St., Vancouver, British Columbia, Canada V6H 3V4.)

COMMENT. These authors have previously found an association between the prolonged use of antimotility drugs and the likelihood for progression of $E$ coli enteritis to hemolytic-uremic syndrome. Systemically absorbed verotoxins are thought to be responsible for the multiple organ involvement. A food reservoir and improper handling are the most likely vehicles for transmission of the E coli.

\section{TREMOROGENIC TOXIC ENCEPHALOPATHY}

A 16 year old boy who developed tremorogenic toxic encephalopathy as a result of inhalation and/or ingestion of mouldy silage containing aspergillus fumigatus, flavus and clavitus is reported from Halifax, Nova Scotia and Kingston, Ontario, Canada. Malaise, fatigue and headache were followed by fever, chills and vomiting. On recovery from these symptoms the boy had progressive dullness of mentation, an incapacitating tremor and rigidity. He was disorientated, his fund of knowledge was reduced and he could not add 2 digit numbers. The trembling and encephalopathy resolved after 7 days and his recovery has appeared to be complete. (Gordon K, Masotti R, Waddell W. Tremorogenic toxic encephalopathy: a role of mycotoxins in the production of CNS disease in humans? Ann Neurol Sept 1992; 32:453 (abstr).)

COMMENT. Reye's syndrome has been attributed to the ingestion of aflatoxins, a form of naturally occurring mycotoxin found on corn (Dvorackova I et al. Aflatoxin and encephalopathy with fatty degeneration of viscera (Reye). An Nutr Aliment 1977; $\underline{31}$ :977-989.) Other foods sometimes contaminated by the aspergillus flavus and aflatoxins include peanuts, rice, cereals, soybeans and peas. Corn produced in southeastern United States has contained more than 20-100 ppb aflatoxin in $30 \%$ of samples tested. The tremorogenic mycotoxins induce rye grass staggers and bermuda grass tremors in sheep and cattle, but more commonly the aflatoxins are known for their effects on the liver and kidneys of animals and humans. 